\title{
Hacia un concepto interdisciplinario de la familia en la globalización
}

\section{Towards an interdisciplinary concept of family in Globalization}

\section{EDUARDO OLIVA GÓMEZ}

Doctor en Derecho, Abogado. Profesor investigador y Jefe de la División de estudios superiores de posgrados de la Facultad de Derecho y Ciencias Sociales de la Universidad Autónoma del Estado de Morelos, México.

posgradoderecho@uaem.mx

\section{VERA JUDITH VILLA GUARDIOLA}

Magister en Educación Superior. Abogada y Psicóloga. Doctorante en Derecho y Globalización.

Docente de la Universidad Autónoma del Estado de Morelos, México.

veravilla@gmail.com

Recibido: Septiembre 13 de 2013

Aceptado: Noviembre 25 de 2013

\section{RESUMEN}

La familia como grupo social, ha cambiado en cuanto a su estructura, formas y modelos, ha incorporado nuevas costumbres como consecuencia de la dinámica transferencia social propia de la globalización, en este artículo, se pretende conducir al Derecho y a las disciplinas en general, hacia una reflexión amplia e incluyente de muchos aspectos que modifican el concepto de esta institución en tiempos de posmodernidad. Para efectos de realizar un estudio más incluyente de las diferentes tendencias, a la luz de los principios propios de los conceptos posmodernos y con la plena observancia de las formas históricas que de ella han existido, se iniciará este análisis partiendo de la base sintáctica del término familia, para posteriormente abordar su estudio desde las perspectivas de la biología, sociología, psicología, economía y del derecho, y concluir con una nueva conceptualización interdisciplinaria e incluyente de sus actuales tendencias de desarrollo.

Palabras Clave: Familia, interdisciplinariedad, Sociedad, Modernidad, Modernización, Posmodernidad, Globalización, Evolución, Conceptualización

\begin{abstract}
Family, as a social group, has changed in terms of structure, shapes and patterns. It has incorporated new habits as a result of the transfer of social dynamics of globalization. This article is intended to analyze a broad and inclusive reflection of many aspects that modify the concept of this institution in postmodern times from a law and other disciplines perspectives.

For purposes of a more inclusive study of the different trends in the light of the principles inherent in postmodern concepts and with full respect for the historical forms of it have existed, this analysis will begin starting from the syntactic basis of the term family and then to address their study from the perspectives of biology, sociology, psychology, economics and law, and conclude with a new interdisciplinary and inclusive conceptualization of their current development trends.

Keywords: Family, interdisciplinary, Society, Modernity, Modernization, Postmodernism, Globalization, Evolution, Conceptualization.
\end{abstract}




\section{Introducción}

Resulta común, en términos científicos, hablar de familia, desde el inicio de los tiempos como la célula, conjunto o grupo originario de la sociedad; grupo que se ha configurado en términos conservadores $u$ ortodoxos, por todas aquellas personas con las cuales se comparten objetivos de vida así como algún parentesco (de consanguinidad o no): madre, padre, abuelos, hermanas y hermanos, tías y tíos, primas y primos.

También ha sido considerado el espacio que permite en forma integral, a cada individuo, el convivir, crecer y compartir con otras personas, los valores, normas, creencias, tradiciones, comportamientos, conocimientos, experiencias y afectos que resultan indispensables para su pleno desarrollo en la sociedad.

En el estudio de la familia, los autores han considerado además los roles que sus miembros despliegan considerando que

Desde su origen, la familia tiene varias funciones que podríamos llamar universales, tales como: reproducción, protección, la posibilidad de socializar, control social, determinación del estatus para el niño y canalización de afectos, entre otras. La forma de desempeñar estas funciones variará de acuerdo a la sociedad en la cual se encuentre el grupo familiar. (Pérez Lo Presti, A y Reinoza Dugarte, M, 2011. P. 629).

Debido a la confluencia de intrínsecos aspectos a su naturaleza como lo son el aspecto histórico, político, socio-cultural y por el desarrollo psico-afectivo de sus miembros, cada familia es única y diferente, no sólo por las relaciones, roles y el número de personas que la forman, sino también por las actividades y trabajos que realizan o la manera en que se organizan y proyectan.

\section{Concepción etimológica de la familia}

De acuerdo con los científicos, existen varias versiones que dan cuenta del origen etimológico de la palabra familia, sin que haya verdadera unidad de criterios frente a este aspecto, algunos consideran que la palabra Familia proviene del latín familiae, que significa "grupo de siervos y esclavos patrimonio del jefe de la gens"

En concepto de otros, la palabra se derivada del término famŭlus, que significa "siervo, esclavo", o incluso del latín fames (hambre) "Conjunto de personas que se alimentan juntas en la misma casa y a los que un pater familias tiene la obligación de alimentar"
Bajo esta concepción se presumía la inclusión de la esposa y de los hijos del pater familia, a quien legalmente pertenecían en cualidad similar a un objeto de su propiedad, hasta que como concepto integrador (de cognados -vinculados por lazos de sangre- y agnados -con vínculos civiles-), acabó siendo subsumido y reemplazado inicialmente por la conceptualización y forma grupal de la gens, que históricamente precedió a otras formas más avanzadas como las familias punalúa, sindiásmica, poligámica, poligámica, monogámica y la actual o posmoderna; todas ellas con características organizativas distintas pero siempre conceptualizadas de manera similar.

\section{Concepto genérico de familia}

Desde una concepción tradicional, se puede observar que "la familia ha sido el lugar primordial donde se comparten y gestionan los riesgos sociales de sus miembros" (Carbonell, José et al 2012. P.4)

En contraste con lo anterior y en un sentido aparentemente amplio pero realmente restringido desde el aspecto de los vínculos que le sirven de factor integrador, "la familia es el grupo de personas entre quienes existe un parentesco de consanguinidad por lejano que fuere". (De Pina Vara, R. 2005. P. 287).

Se ha definido también según autores como Luciano Febvre (1961) como "el conjunto de individuos que viven alrededor de un mismo lugar..." que continúa diciendo que "La familia se define como el conjunto de individuos que viven alrededor de un mismo hogar" (Febvre, 1961.P.145) definición que muestra la amplitud de su cobertura conceptual, pero con una cierta limitación desde el aspecto espacial, que no se ajusta a las nuevas realidades que impone la globalización con sus características migratorias y de movilidad de sus integrantes.

Con el pasar de los tiempos, se han visto fortalecidos además ciertos vínculos de solidaridad entre los miembros del grupo; que han sido profundamente observados en el plano de la psicología, dados los sentimientos de convergencia y afecto que esa situación crea como dinámica grupal y que van más allá de una relación basada en la consanguinidad. Se toma así la idea de la familia en sentido amplio que coincide con el concepto de la gens (linaje).

La familia ha tenido connotaciones más restringidas, a las que se ha llegado después de una larga evolución y que comprende fundamentalmente a los cónyuges y a los hijos de éstos, que viven en un mismo lugar.

La familia se seguirá por siempre modificando pues en concepto de autores como Morgan, "es el elemento activo; 
nunca permanece estacionada, sino que pasa de una forma inferior a una forma superior a medida que la sociedad evoluciona de un grado más bajo a otro más alto" (Engels, 2008. P. 9) Por ello, no puede ser estudiada como una institución inmutable y tradicional, se requiere que de manera continua se reconsidere su forma y definiciones bajo las nuevas dinámicas, que cada vez le confieren nuevos contornos y esguinces.

La Familia no puede analizarse perennemente como un concepto ideal a la luz del criterio platónico, porque esto es contrario a su naturaleza; en opinión de Federico Engels, "el proceso evolutivo de la familia en la historia primitiva consiste en estrecharse constantemente el círculo en el cual reina la comunidad conyugal entre los dos sexos y que en su origen abarca la tribu entera" (Engels, 2011.P.34) concepto que ya no se ajusta a la dinámica actual del proceso en cuestión.

La familia en su forma evolucionada se ha presentado unida a la institución del matrimonio que atribuye estabilidad social y legal al grupo formado como consecuencia del apareamiento del hombre y la mujer, aunque no se niega la posibilidad de que como hecho existe y ha existido la familia no matrimonial.

Adicionalmente y de acuerdo con Rousseau,

La sociedad más antigua de todas, y la única natural, es la de una familia; y aún en esta sociedad los hijos solo perseveran unidos a su padre todo el tiempo que le necesitan para su conversación. Desde el momento en que cesa esta necesidad, el vínculo natural se disuelve (Rosseau, J. 2008.P.9).

Los hijos, libres de la obediencia que debían al padre, y éste, exento de los cuidados que debían a los hijos recobran igualmente su independencia. Si continúan unidos, ya no es naturalmente, sino por su voluntad; y la familia misma no se mantiene sino por convención.

La referida libertad es una consecuencia de la naturaleza del hombre, por lo que su principal deber es procurar su propia conservación, sus principales cuidados los que se debe asimismo; y luego que está en estado de razón, siendo él solo el juez de los medios propios para conservarse, llega a ser por este motivo su propio dueño.

Es pues la familia, si así se quiere, el primer modelo de las sociedades políticas: el jefe es la imagen del padre, y el pueblo es la imagen de los hijos; y habiendo nacido todos iguales y libres, solo enajenan su libertad por su utilidad misma.
"Toda la diferencia consiste en que una familia el amor del padre hacia sus hijos le paga el cuidado que de ellos ha tenido; y en el estado, el gusto de mandar suple el amor que el jefe no tiene a sus pueblos". (Rosseau, J. 2008.P.10)

De ahí es posible concluir que la familia está tradicionalmente constituida por el grupo de personas que proceden de los progenitores (sentido amplio) y que las relaciones jurídicas que existen entre sus miembros tienen como fuente el matrimonio y la filiación matrimonial o extramatrimonial.

Con plena observancia de la doctrina aristotélica, prehispánica y moderna, Virginia Aspe conceptúa que "La familia, como realidad metafísica cuyo acto es el fin o perfección de la comunidad que conforma supone un desarrollo que ya no es competencia filosófica sino de análisis e indagación del científico familiar". (Aspe, Armella, 2006.P.34)

Es así como el concepto de la familia puede emitirse desde una perspectiva sociológica y desde una perspectiva jurídica. Los sociólogos definen a la familia afirmando que es un grupo caracterizado por una relación sexual suficientemente definida y permanente para promover a la procreación y educación de la prole; también se le conceptúa como a la agrupación relativamente permanente y socialmente autorizada de padres e hijos.

Condensan su atención los sociólogos

en la actividad gene nómica de la familia, porque han advertido que en todos los tiempos y lugares, trascendiendo las vicisitudes y eventualidades del cambio de costumbres, los hombres han regularizado e institucionalizado la actividad generadora por medio de la familia, constituyendo esto lo que los antropólogos americanos llaman un pattern universal de cultura. (Gustavikno P. E.1987.P. 13.)

La familia está presente en la vida social. Es la más antigua de las instituciones humanas y constituye el elemento clave para la comprensión y funcionamiento de la sociedad. A través de ella, "la comunidad no sólo se provee de sus miembros, sino que se encarga de prepararlos para que cumplan satisfactoriamente el papel social que les corresponde. Es el canal primario para la transmisión de los valores y tradiciones de una generación a otra" (Gustavikno P. E. 1987. P. 13.)

Más que un solo tipo de familia o una "familia ideal", existen "muchas familias" que representan diversas formas de crecer, convivir y relacionarse. "El interés de la familia no siempre coincide con el egoísmo de cada uno, 
y por esto la organización familiar viene regulada por numerosas normas inderogables, de orden público". (Trabucchi, A. 2008. P.53.). Mientras mayor es la libertad que el derecho garantiza a los sujetos, sobre todo, en su determinación al cumplimiento de los actos familiares, más pequeña es la autonomía que se les reconoce en la regulación de la relación de familia.

Se destaca el concepto de familia realizado por Montero Duhalt, S (1992. P. 2), al referir que "La familia constituye un campo clave para compresión del funcionamiento de la sociedad"

Cuando un ser humano nace, comienza en el seno de la familia a aprender las normas del comportamiento que se consideran adecuadas, buenas o morales; así desde pequeños se les enseñan las creencias religiosas y se les infunde una escala de valores determinados y una serie de normas de conducta.

Se socializa de este modo al nuevo miembro haciéndose apto para la vida en sociedad a la que pertenece "de acuerdo con sus diversas etapas de desarrollo, hasta que alcanza madurez biológica y social, por lo que el individuo se encuentra preparado para formar él mismo su propia familia y recomenzar el ciclo que nutre la vida social" (Montero Duhalt, S.1992. p. 2)

En la actualidad, la familia funciona por su propia dinámica, con nuevas concepciones, en las que ha cobrado gran relevancia la planificación familiar y el control de la fecundación, así como otras cuestiones que se deben recoger en un cuerpo legal; También ahora su concepción implica distintos aspectos, y es por tanto considerada como un núcleo natural, económico y/o jurídico de la sociedad.

La familia es la unidad interna de dos o más elementos del grupo humano -padres e hijos-, que se constituyen en comunidad a partir de la unidad de una pareja, siendo uno de los grupos sociales que requieren con prioridad de una atención especial.

Cada familia es única, como distintos son sus miembros, con diferentes modos de pensar y de sentir, sin embargo, algunas de las problemáticas más comunes por las que atraviesa el grupo en términos generales, tienen que ver con el fortalecimiento de la capacidad de la familia para atender sus propias necesidades, el equilibrio entre el trabajo y las responsabilidades familiares; la reducción de la violencia doméstica y el alivio de la pobreza.

Toda familia auténtica tiene un "ámbito espiritual" que condiciona las relaciones familiares, casa o contextos de vida común, vínculos de sangre, afectos recíprocos, vínculos morales que la configuran como "unidad de equilibrio humano y social.

Se puede decir, que la familia es el medio específico en donde se genera, cuida y desarrolla la vida. En este sentido se convierte en el "nicho ecológico por excelencia, y por qué no, en la primera escuela de la humanización, de transmisión generacional de valores éticos, sociales y culturales que aporta un sentido mucho más amplio a la misma existencia humana" (Planiol y Ripert, 2002. p.178.)

En este marco de referencia se toma a la familia como un sistema abierto y activo que se desarrolla entre personas de diferente sexo y en diferentes estadios de maduración física y mental; es un sistema natural de seres humanos en el cual las personas se encuentran relacionadas por medio de lazos sanguíneos y de afinidad, reunidos en un lugar común delimitado cultural y geográficamente para satisfacer las necesidades básicas, físicas y psicológicas de sus miembros.

Ciertamente, "La familia es un sistema autónomo, pero al mismo tiempo, es interdependiente, no tiene la capacidad de auto-abastecerse por sí sola, necesita a la sociedad y ésta a la familia, porque su retroalimentación hace posible su permanencia" (Planiol y Ripert, 2002. p.178.) de allí la importancia de su protección jurídico-social.

Es importante concebir abiertamente a la familia como un grupo social básico creado por vínculos de parentesco, presente en todas las sociedades. Idealmente, la familia proporciona a todos sus miembros: Cuidados y protección, compañía, seguridad y socialización.

\section{Formas familiares}

La forma o estructura, así como el papel de la familia, varía según la sociedad. Con todo, la familia nuclear (dos adultos, hombre y mujer, con sus hijos) es la unidad principal de las sociedades.

En algunas otras comunidades, el núcleo está integrado como una gran familia, con abuelos y otros familiares. Una tercera unidad familiar es la familia monoparental, en la que los hijos viven sólo con el padre o con la madre en situación de soltería, viudez o divorcio.

La estructura familiar ha variado con respecto a su forma más tradicional en cuanto a funciones, composición, ciclo de vida y rol de los padres, principalmente por el rol de la mujer, la que por variaciones en su situación económica, se ha visto en la necesidad de salir de su hogar en busca de sustento familiar. 
Es importante tener presente al tiempo de revisar su concepción social,

que en la actualidad el concepto de familia presenta una transformación sustancial en atención a los nuevos modelos sociales en que ésa se desarrolla, ya no se considera integrada exclusivamente por los parientes y los cónyuges como tradicionalmente se les identificaba, es decir, es decir, vinculada por matrimonio y relaciones parentales; ahora y en atención a la dinámica social, se contemplan otras formas de relaciones humanas donde los miembros que la integran se encuentran vinculados por lazos de afecto, de respeto, de convivencia y de solidaridad (Oliva Gómez, E. 2013. P.63).

Por lo cual debe considerarse la integración al nuevo concepto familiar, de grupos como las uniones maritales de hecho o integrados por personas del mismo sexo, siempre que se encuentren unidos por los lazos descritos y tengan los fines de convivencia y solidaridad constantes. Díaz de Guijarro, (citado por Frode Gómez, K. 2007.p. 22.) lo define como

...el conjunto de instituciones jurídicas de orden personal y patrimonial que gobiernan la fundación, la estructura, la vida y la disolución de la familia" y afirma que, es "el conjunto de normas que, dentro del código Civil y de las leyes complementarias, regulan el estado de familia, tanto de origen matrimonial como extramatrimonial, los actos de emplazamiento en este estado y sus efectos personales y patrimoniales.

Existen numerosos intentos de definir al derecho de familia con mayor exactitud, los cuales no han logrado cabalmente su propósito, porque al precisar el concepto los estudiosos del derecho deben recurrir a nociones controvertidas tales como su contenido y su ubicación en las diferentes ramas del derecho.

Podría parecer que el derecho de familia es especialmente el promotor, ya que sus normas son fundamentalmente de orden público e interés social. Aunque esas normas son obligatorias, su obligatoriedad emana del deber moral y de los principios naturales en que se funda, como la institución humana más antigua y como elemento clave para la comprensión y funcionamiento de la sociedad, ya que a través de ella, la comunidad no sólo se provee de sus miembros, sino que se encarga de prepararlos para que cumplan satisfactoriamente el papel social que les corresponde.
El derecho de familia tiene como fin normar las relaciones familiares así como delimitar los derechos y obligaciones de cada parte integrante del núcleo familiar.

La familia se considera prioridad de orden público, por constituir aquella la base de la integración de la sociedad, asimismo es de orden público la protección legal y judicial de lo económico, social o culturalmente débiles frente a quienes se hallan en la situación contraria.

\section{Concepto de familia desde las diferentes disciplinas}

La concepción real de la Familia no es simple, por tanto su estudio debe ser abordado desde una perspectiva integradora, que permita observarla y comprenderla tal cual como se presenta en la realidad, esto es, bajo una comprensión fenomenológica holística que revele su verdadera identidad, dinámica y desarrollo, incluyente de todos los aspectos que separadamente son objeto de estudio por cada disciplina.

Para considerar los aspectos disciplinarios enunciados, se presentan a continuación los conceptos y fines de la familia más relevantes en algunas disciplinas:

\section{Concepto Biológico}

Como un hecho biológico, la Familia implica la vida en común de dos individuos de la especie humana, de sexo distinto, unidos con el fin de reproducir, y por ende de conservar la especie a través del tiempo.

Desde esta óptica, se puede observar a la familia como una agrupación humana de fines eminentemente biológicos, La familia como hecho biológico involucra a todos aquellos que, por el hecho de descender los unos de los otros, o de un progenitor común, generan entre sí lazos de sangre.

Son fines de la familia, bajo este aspecto:

- La multiplicación con la correspondiente adición de nuevos individuos a la sociedad.

- Generar en la pareja el estadio de total goce de sus funciones sexuales.

- Proporcionar a los hijos un concepto firme y vivencial del modelo sexual, que les permita a futuro en su vida, hacer identificaciones claras y adecuadas de sus roles sexuales.

- Perpetuar la especie humana en el tiempo y espacio. 


\section{Concepto Psicológico}

Para la Psicología, la familia implica un cúmulo de relaciones familiares integradas en forma principalmente sistémica, por lo que es considerada un subsistema social que hace parte del macro sistema social denominado sociedad; esas relaciones son consideradas como un elemento fundamental en el proceso de desarrollo de la personalidad.

De otro lado, se podría definir a la familia para la psicología

...como la unión de personas que comparten un proyecto vital de existencia en común que se supone duradero, en el que se generan fuertes sentimientos de pertenencia a dicho grupo, en el cual existe un compromiso personal entre sus miembros y se establecen intensas relaciones de intimidad, reciprocidad y dependencia (Malde Modino, I, 2012)

Son fines de la familia, bajo este aspecto:

- Proporcionar a todos y a cada uno de sus miembros, seguridad en el campo afectivo.

- Preparar a sus integrantes para el desarrollo de procesos adaptativos.

- Crear hábitos cotidianos y de manejo conductual con responsabilidad.

- Manejar bajo esquemas adecuados las crisis, angustia y en general las emociones y frustraciones, a través del autocontrol.

- Dirigir el desarrollo personal hacia la independencia.

- Canalizar energías y manejar impulsos, la violencia y autoritarismo.

- Proteger a todos sus miembros y prepararlos para la independencia a través de la educación y el respeto.

\section{Concepto Sociológico}

Para la sociología, la Familia se constituye por una comunidad interhumana configurada al menos por tres miembros, "es un conjunto de personas que se encuentran unidos por lazos parentales. Estos lazos pueden ser de dos tipos: vínculos por afinidad, el matrimonio y de consanguinidad como ser la filiación entre padres e hijos" (Definición $\mathrm{ABC}$ )

Observados por su importancia histórico-social, tiene la familia como fines, bajo este aspecto:

- Perpetuar costumbres, cultura e identidad social.

- Reconocer y respetar la autoridad.

- Educar en el lenguaje y en la comunicación escrita, así como el uso del diálogo y en general de la comunicación como medio de solución de conflictos.
- Respetar las normas de social convención y las particulares de cada nucleo familiar.

- Crear una identificación y seguimiento de roles y modelos de conducta social.

- Crear redes familiares y sociales de acompañamiento y desarrollo social.

- Formar parte integrante del grupo social básico.

\section{Concepto Económico}

Para la economía, la Familia se estudia más claramente al considerarla como una "pequeña fábrica" (Becker G, citado por Miró Rocasolano, P) constituye una institución que basa su existencia en la previsión de costos, gastos monetarios y de ingresos, que llevan a sus miembros, por ejemplo, a considerar a cada hijo como bienes de consumo o como generadores en presente de gastos de inversión que se proyectan como inversión a futuro, considerando correlativamente los ingresos que se han de percibir y la asistencia en la enfermedad y vejez. Por lo anterior se cree que en los países más desarrollados hay un más bajo índice de natalidad.

Para la economía, la familia es entonces una unidad al tiempo que un subsistema económico, que fluye socialmente como elemento receptor, a su vez que emisor, de fuerzas, políticas y dinámicas productivas, que se modifican en contraste con los cambios históricos.

En Marx, posee una función e identidad socio-económica que se encuentra supeditada a su ubicación o estatus, esto es, a una distinción económica que obedece a la clase social a la que pertenece (Anton, $\mathrm{A}$ )

Los fines económicos de la familia son:

- Dar a todos y a cada uno de sus miembros seguridad económica.

- Dotar a todos sus integrantes, de los elementos materiales mínimos necesarios para suplir sus necesidades básicas.

- Crear una cultura económica de ahorro y manejo de capital, que le permita subsistir y propender constantemente por su desarrollo económico.

- Preparar a cada individuo para su independencia económica.

- Enseñar el uso y manejo de la moneda y el diseño de estrategias económicas.

\section{Concepto Legal}

Desde la esfera legal, la familia tiene una connotación que se encuentra supeditada a la normatividad misma y por el momento histórico en que se revise; el concepto 
de familia es dinámico y está en constante evolución. La definición legal de este término va a depender de la legislación de cada estado o país, y generalmente se encuentra ubicada en la constitución.

Para algunos,

...el concepto jurídico de familia solo la considera a partir de la pareja, sus descendientes y ascendientes $\mathrm{y}$, cuando descienden del mismo progenitor, incluye a sus parientes colaterales hasta el cuarto grado. Así las cosas, el concepto jurídico de familia responde al grupo conformado por la pareja, sus ascendientes y descendientes, así como otras personas unidas por vínculos de sangre o matrimonio o sólo civiles, a los que el ordenamiento positivo impone deberes y otorga derechos jurídicos. (Baqueiro Rojas, E y Buenrostro Báez, R. 2001. P. 9)

En todo caso, el rol y objetivos familiares desde el aspecto fundamentalmente legal son:

- Crear hábitos de autocontrol y de reconocimiento de roles, normas y autoridad.

- Respetar reglas y normas producto de las convenciones sociales y particulares.

- Reconocer los acuerdos y roles de los padres e hijos entre si y con el contexto, en la esfera de la mutua responsabilidad.

- Diferenciar y respetar los derechos de todos los miembros de la familia y de la sociedad, haciendo distinción entre los miembros por edad, funciones, ubicación e intereses.

- Identificar y cumplir los deberes que les corresponden a sus miembros en su contexto.

- Asumir la comunicación como principal herramienta de prevención y manejo o solución de conflictos.

\section{Hacia un nuevo concepto interdisciplinario de Familia, en la Posmodernidad y globalización}

Luego de conocer los criterios conceptuales monodisciplinares y los fines que desde cada esfera académica se tienen previstos para el ámbito familiar, se propone por los autores, la adopción de un concepto de familia más incluyente de sus dinámicas internas y de las influencias externas que experimenta, que le permita ajustarse a los reales deseos, necesidades y condiciones de las parejas originarias, en tiempos de gran influencia informática y de la cultura global.

La Familia es el grupo de dos o más personas que coexisten como unidad espiritual, cultural y socio-económica,que aún sin convivir físicamente, comparten necesidades psico-emocionales y materiales, objetivos e intereses comunes de desarrollo, desde distintos aspectos cuya prioridad y dinámica pertenecen a su libre albedrío: psicológico, social, cultural, biológico, económico y legal.

La sociedad moderna es abierta al tiempo que heterogénea, el concepto enunciado rompe el esquema tradicional de la familia, ligado a la concepción matrimonial y religiosa, se observa una institución social de orden universal, pues se encuentra con diversidad de estructuras pero siempre presente en todas las cultural, pueblos y sociedades; es un núcleo social fortalecido y no en crisis.

Bajo esta nueva óptica, se destacan los siguientes aspectos:

- La distinción de la familia como grupo, que es para la psicología el "conjunto de personas unidas por un fin común o por sentimientos de afecto y de afiliación" (Grupo Editorial Planeta. 1986. P.30) y que a diferencia de las masas. Está constituido por personas que tienen un trato social -interacción- frecuente y que están conscientes de que entre ellos existe una identidad común.

Por lo anterior y siguiendo la teoría aplicable de la psicología social, la familia es un grupo primario, con reglas particulares permeadas por las costumbres, usos, cultura en general, influenciada o no por la información y percepción de modelos externos visualizados a través de diferentes medios, entre ellos los de comunicación.

Se diferencia entonces la familia como grupo, de las masas de diferentes tipos como la popular, auditorios, públicos o muchedumbres, donde no siempre hay comunicación interna, ni hay un sistema continuado de reglas, como tampoco hay permanencia, roles ni fines a largo plazo.

Como grupo, la familia se constituye en un ambiente restringido e íntimo de cada persona, donde se muestra tal cual es, sin mayores limitaciones o restricciones que las impuestas por la ley, en espacios reales o virtuales de interacción, recreados bajo sus propias reglas.

Si bien es cierto para algunos una sola persona se puede considerar familia, los autores coincidimos en que para que esta unidad social pueda cumplir las metas sociológicas e institucionales propuestas, debe ser un espacio de convergencia, aprendizaje e interacción, por lo que no estamos de acuerdo con que una sola persona pueda configurarse como familia. 
Por su naturaleza,

el ser humano necesita pertenecer a una comunidad y para ello puede mantener lazos muy estrechos con algunas personas durante extensos períodos de la vida. Con otras puede haber una relación menos estrecha, aunque igualmente sostenible con el paso del tiempo.Es por la necesidad de tener lazos afectivos que deseamos permanecer dentro de un ambiente personal y familiar que nos proporcione un terreno relativamente seguro, alejado de riesgos para enfrentar.(República de Colombia, Ministerio de Educación Nacional. Familia y comunidad)

- Al no distinguir el sexo ni forma originaria de las personas que conforman el grupo, la definición incluye a seres humanos de igual o diferente sexo, cuya unión se encuentre formalizada o no, provengan de igual o diferentes lugares, por tanto, en ella no hay discriminación por razón del sexo e incluye a las familias homosexuales y heterosexuales, sin importar sus edades o creencias políticas o religiosas, si se encuentran unidas por matrimonio o en convivencia informal para el derecho pero en forma constante $\mathrm{y}$ con fines loables comunes, y sin importar su raza, condición social o nacionalidad, esto es, sin discriminación alguna.

- La familia se constituye en una unidad espiritual, cultural y socio-económica, dado que precisamente como grupo único, crea lazos que van más allá de lo físico y emocional, su sentido de pertenencia le permite a cada miembro sentirse parte del otro, compartir sueños y expectativas, así como sufrimientos y dolor, las costumbres varían de una familia a otra haciendo a cada una pieza social única, que engrana en el tejido cultural y económico de cada contexto.

Es a la vez un grupo de producción que como una pequeña unidad de producción, responde a las necesidades y condiciones sociales en la medida de sus posibilidades y creencias, con inversión permanente en sus miembros y recaudación de producción, ahoro y reinversión social y por ende cultural.

Como unidad cultural, cada familia se integra como un constructo único, donde elementos como la educación, costumbres y orígenes, se conjugan dando lugar a elementos sociales únicos y diversos, por eso no hay familias idénticas.

Por los aspectos estudiados, la familia es más que una sociedad, es una unión, que integra espacios y aspectos, tanto visibles como desconocidos de las personas.
- $\quad$ Sus integrantes comparten necesidades psicoemocionales y materiales, por cuanto aún sin hablar, se conocen y pueden sentir sus alegrías y problemas, luchan por cumplir sus objetivos pues tienen intereses comunes de desarrollo, lo que les hace luchar de manera conjunta por sus ideales; las metas de cada uno de sus integrantes son compartidas por los demás, en principio ninguno de sus miembros se sustrae o hace caso omiso a las necesidades psicológicas y materiales de los demás miembros del grupo.

En sociedades matriarcales se observa con claridad -grupos indígenas de la actualidad, como los wayúu radicados en el departamento de la Guajira, al norte de Colombia-, que hay corresponsabilidad material por los errores y delitos cometidos por todos y cada miembro de la familia, así, en todas las culturas, en mayor o menor grado, se observa el grupo familiar como fuente y sustento emocional y material de sus integrantes. Por ello, aun cuando los amigos fallen, la familia generalmente está allí como grupo de soporte emocional y material ante cualquier adversidad.

- $\quad$ El hecho de vivir o no de manera permanente bajo el mismo techo no impide que surjan y se mantengan lazos familiares. En tiempos de interconexión satelital, y de constante migración internacional, es más fácil inclusive establecer y mantener estos vínculos, pues es cada vez más fácil y común el conocer personas y establecer lazos y relaciones afectivas a través de la comunicación, y llegar a construir parejas o familias que surgen de la interacción a través de estos medios.

Las telecomunicaciones han modificado para incluirse como una de las formas sociales de compartir y relacionarse, por tanto una concepción moderna de familia debe considerarle como un agregado cultural de nuestros tiempos.

- La prioridad de los elementos y fines previstos desde la esfera de cada disciplina, esto es, de índoles psicológico, social, cultural, biológico, económico y legal, así como la dinámica que bajo estos objetivos se sigan, hacen parte de la libertad de cada familia; así, encontraremos que para alguna familia, es más importante en un momento o no de sus vidas el elemento biológico, pues pueden en un primer momento tener hijos, o para nuevas parejas de personas mayores, esta no será una prioridad ni un elemento o fin común, excluyéndose de su dinámica familiar.

De la misma manera la capacitación de sus miembros podrá encontrarse en la fase de máxima importancia durante algún tiempo, si no se han desarrollado académicamente 
en forma plena al tiempo de la unión; por eso, luego de cumplir uno a uno sus objetivos, cambiarán sus prioridades.

De acuerdo con lo conceptuado por Maslow (Elizalde Evia, A et al, 2006) los seres humanos se motivan cuando sienten deseos, anhelo, voluntad, ansia o carencia, y precisamente los grados mayores o menores de fuerza, firmeza o potencia de estos elementos generan los distintos grados de necesidades humanas, con una jerarquización para el autor, de forma piramidal.

Las necesidades son resultantes de las carencias, por tanto hay diferentes clases de necesidades, que según Maslow (Elizalde Evia, A et al, 2006) pueden clasificarse así:

(a) Necesidades deficitarias o inferiores, estas son: necesidades fisiológicas; necesidad de seguridad; de amor y de pertenencia; y de estima; si se produce una distorsión en ellas se pueden generar problemas psicológicos y/o fisiológicos. (b) Necesidades de desarrollo o superiores que se orientan hacia el logro de la autorrealización, las cuales no son tan poderosas como las necesidades fisiológicas; éstas pueden dañarse o perder su orientación más fácilmente que las necesidades primarias y requieren de un gran apoyo de las influencias exteriores (Elizalde Evia, A et al, 2006)

Las necesidades van cambiando en orden a la satisfacción de las carencias particulares de cada persona o grupo, por lo tanto, no es posible temporizar o jerarquizar las necesidades familiares, pues su orden y dinámica interna es única, tanto como sus motivaciones.

\section{Conclusión}

Como conclusión de esta reflexión, solo es dable recordar que cada familia tiene su propia composición, dinámica y reglas, así como cultura y economía, por tanto su concepción debe ser tan flexible como la institución misma, contemplando en ella elementos o integrantes tan diversos como sus integrantes lo deseen.

Se deja entonces abierto el debate social que permita despejar el horizonte teórico, al concebir familias disímiles con integrantes de iguales o diferentes sexos, de iguales o diferentes orígenes territoriales, así como de la misma proveniencia biológica o no, unidos formal o informalmente, incluyéndose en el núcleo social elementos familiares mixtos como los que se integran en las llamadas familias amalgamadas.

La ciencia jurídica debe dejar en libertad a la familia para integrarse o reintegrarse como quiera, con actos de amor antes que con formalidades, sin mayores compromisos de composición y permanencia que los que les impongan su conciencia y amor.

\section{Referencias}

Antón, A. (1999) Mujeres y Familia en Marx. Universidad Autónoma de Madrid. Disponible en http://www.uam.es/ personal_pdi/economicas/aanton/publicacion/otrasinvestigaciones/mujerenmarx.htm Consultado el 23 de enero de 2014

Aspe Armella, V (2006) La noción aristotélica de ciencia subalterna: Hacia una metodología transversal del género "familia". En: Aspe Armella, V (Compiladora). Familia: Una jornada sobre su naturaleza, Derechos y Responsabilidades. México. Editorial Porrúa - Universidad Panamericana.

Baqueiro Rojas, E y Buenrostro Báez, R (2001) Derecho de Familia y Sucesiones. Colección de textos jurídicos universitarios. Segunda edición. México. Editorial Oxford.

Becker, G. Citado por Miró Rocasolano, P. La Familia como institución económica. Disponible en http://www.eumed. net/cursecon/1/instfamilia.htm. Consultado el 23 enero de 2014

Carbonell, J; Carbonell, M y González Martín, N (2012) Las Familias en el siglo XXI: Una mirada desde el Derecho. Universidad Autónoma del Estado de México, Instituto de investigaciones jurídicas. Serie: Estudios Jurídicos, Núm. 205. Coordinadora México. Editorial: Elvia Lucía Flores Ávalos.

De Pina Vara, R (2005) Diccionario de Derecho. Editorial, Porrúa. México. 
Definición ABC. Definición de Familia disponible en http://www.definicionabc.com/social/familia.php\#ixzz2DToJC0ei. Consultado el 15-10-2012.

Díaz De Guijarro, Citado por Frode Gómez, K. (2007) Derecho Procesal familia. México.

Disponible en http://definicionlegal.blogspot.mx/2011/06/concepto-biologico-de-familia.html. Consultado el 12 de Octubre de 2012.

Elizalde Evia, A, Martí Vilar, M y Martínez Salvá, F. (2006). Una revisión crítica del debate sobre las necesidades humanas desde el enfoque centrado en la persona. Revista de la Universidad Bolivariana, vol. 5, núm. 15, 2006 Universidad Bolivariana Chile. Disponible en http://www.redalyc.org/pdf/305/30517306006.pdf. Consultado el 23 de enero de 2014

Engels, F (2011) El origen de la Familia, la Propiedad Privada y el Estado. Editorial Colofón S.A. de C.V. México D.F. Reimpresión.

Febvre, L (1961) La tierra y la evolución humana. Introducción geográfica a la historia. Segunda edición en español. Colección la evolución de la humanidad. Tomo 4. México. Unión Tipográfica. Editorial Hispanoamericana.

Grupo Editorial Planeta. (1986) Diccionario de Psicología. Edición fuera del comercio, incluida en la Gran Enciclopedia de la Psicología: El conocimiento de si mismo y de los demás. México. Editorial Planeta.

Gustavikno, E (1987) Derecho de Familia Patrimonial. Bien de Familia. Tomo I. Segunda Edición. Argentina.

Malde Modino, I. Qué es la familia. Definición e implicaciones del concepto http://www.psicologia-online.com/monografias/separacion-parental/que-es-la-familia.html. Consultado el 15 de Octubre de 2012.

Montero Duhalt, S (1992) Derecho de Familia. México. Editorial. Porrúa.

Oliva Gómez, E. (2013) El Divorcio incausado en México. México. Moreno Editores

Otero, $\mathrm{O}$ iSe siente solo o sola? Los lazos afectivos. Disponible en: http://www.colombiaaprende.edu.co/html/familia/1597/article-95046.html

Pérez Lo Presti, A y Reinoza Dugarte, M. (2011) El educador y la familia disfuncional. En: Revista Educere. Ediciones Universidad de los Andes. Facultad de Humanidades y Educación. Año 15 №22. Septiembre-diciembre de 2011. Mérida, Venezuela.

Planiol y Ripert (2002) Tratado Práctico de Derecho. Instituto de Investigaciones Jurídicas. México,

Rousseau, J. (2008) El Contrato Social. Editorial. Maxtor. Reimpresión

Trabucchi, A (2008). Instituciones de Derecho civil. Universidad de Pavía. TSJDF. México, D.F.

Zeledón Ruiz, M. (2005). Cultura familiar en los procesos de configuración de la personalidad moral de los niños y niñas de 5 a 6 años: hacia la construcción de una ciudadanía democrática, (España) Consulta: 03-10-12. Disponible en http://dialnet.unirioja.es/servlet/tesis?codigo $=3460$ 